\title{
Predictors of Outcome in Acute Exacerbation of Chronic Obstructive Pulmonary Disease
}

\author{
Article by Suhail Neliyathodi \\ Professor and HOD, Department of Pulmonology, MES Medical College, \\ Perinthalmanna, Kerala, India \\ E-mail: sneliyath@yahoo.com
}

\begin{abstract}
Background: Exacerbations are the important cause for morbidity and mortality in COPD. The factors related to the outcome of COPD exacerbations and prognosis help to find them at risk patients.

Objectives: To find out the important factors associated with prolonged hospital stay, NIV usage and mortality following admission for COPD exacerbation.

Methods: The study is a prospective observational study involving 114 patients admitted with COPD exacerbation in MES Medical College, Kerala, India during a time period from 1st October 2013 to 31st March 2016. Disease severity accessed by FEV1, GOLD class, mMRC dyspnoea scale, $A B G$ parameters and electrolyte disturbances.

Results: Out of 114 patients' enrolled 8 patients expired during the hospital admission. 50 patients (43.9\%) had prolonged hospital stay ( $>5$ days) and the factors associated with it are low FEV1, higher respiratory rate and high blood urea level. 24 (38.1\%) of the 63 patients on NIV had prolonged NIV usage ( $>5$ days). Serum potassium value $<4$ is the only factor associated with prolonged NIV usage. Of 74 patients followed up for 3 months 19 (25.7\%) expired during the period. FEV1<36\% and Respiratory rate $>29$ are the factors independently associated with three months mortality.

Conclusions: The factors associated with in-hospital mortality are higher respiratory rate, lower FEV1 and high blood urea level. Hypokalemia is associated with prolonged days of NIV usage. Three month mortality following AECOPD is related to higher respiratory rate, and low FEV1 value. The mean cost of an AECOPD in our study is $\$ 134$.
\end{abstract}

Keywords: COPD Exacerbation, Predictors, Outcome.

\section{Introduction}

An exacerbation of COPD is an acute event characterized by worsening of patient's respiratory symptoms that is beyond normal day to day variations and leads to change in medication.1,4,5,6 Exacerbations of COPD are important events in the course of the disease because they 1) negatively affect the patient's quality of life7,8, 2) have effects on symptoms and lung function that take several weeks to recover from9, 3) accelerate the rate of decline of lung function10,11, 4) are associated with significant mortality, particularly in those requiring hospitalization and have high socioeconomic costs1,12.

Mortality following an exacerbation has been found to be related to $\mathrm{PaO} 2 / \mathrm{FiO} 2$, serum albumin, BMI, age, quality of life, specific co-morbidities, exacerbation frequency, $\mathrm{PaCO}$, LTOT use and FEV1. Angeliki M Tsimogianni et al found that length of hospital stay was related to BMI, MRC dyspnoea scale, and Long Term Oxygen Therapy (LTOT) 4. The data published by National Commission on Macroeconomics and Health in India, the per capita expenditure on COPD was Rs.42664 in 2006, and is expected to increase to Rs.62630 in 2016. Predictors of outcome following COPD exacerbations in India in general and Kerala in particular are not available. Published studies on outcome parameters other than mortality are almost nil2-5. Our study done to obtain the significance of severity of illness and the outcome in acute exacerbation of COPD. To investigate the relationship between metabolic factors and mortality in acute exacerbation of COPD. Also to obtain the cost per exacerbation. 


\section{Materials and methods}

Study design is a prospective observational study involving all patients admitted with acute exacerbation of COPD in MES Medical college Hospital, Perinthalmanna, Kerala during a period from 1st October 2013 to 31st March 2015. Diagnosis of COPD was based on GOLD COPD guideline. Inclusion Criteria- all diagnosed cases of COPD > 35 years and exacerbation according to GOLD COPD guidelines and exclusion of other significant respiratory illness. Ethical clearance was obtained from institutional ethics committee. All patients were selected after obtaining a written informed consent. Treatment is given as per GOLD COPD guidelines. Data was collected using a profoma. All patients undergo detailed clinical examination, chest x-ray, ABG analysis, spirometry (done using Vitalograph Model 6800 Pneumotrac), blood investigations including electrolytes sodium, potassium and magnesium. Spirometry will be assessed before discharge from hospital if no recent test done within six months, or in next visit. Those requiring NIV are managed in the ward unless no other indication for ICU admission.

Immediate outcome were accessed in terms of in-hospital mortality, prolonged hospital stay, NIV for $>5$ days and the need for invasive mechanical ventilation. The primary outcome is three month mortality following COPD exacerbation. The total cost of the exacerbation is assessed at the time of discharge. Three month survival is assessed by telephonic contact with the patients phone number provided. Of the total 114 cases participated in the study, 40 patients lost follow up. So three month survival is analysed with 74 patients only.

Data was entered using excel and analysis was done using SPSS version 16 . Non continuous data was expressed as frequencies, continuous variables are reported as mean plus or minus standard deviation. Study group are split on the basis of the basis of outcome. Continuous variables were analysed using students $t$ test. Baseline parameters which are significant in univariate analysis are analysed using multiple logistic regression method to determine the independent predictors of each outcome. ROC analysis was done to find out the best cut off value with maximum sensitivity and specificity for each parameter. All parameters with $\mathrm{p}<0.05$ were taken as significant. Multiple logistic regression and cox regression analysis were done to find out the independent variables which predict the three month mortality.

\section{Results}

In our study a total of 114 patients were selected as per inclusion and exclusion criteria and those who fails to give consent. Majority $(109,95.6 \%)$ of our patients belongs to male gender. The mean age of the patients in this study is 64.7 and 56 (49.1\%) belongs to the age group 6179 years. Of 114 patients studied, all patients have dyspnea and cough. Dyspnea was analysed using mMRC dyspnea scale. 32(28.1\%) of patients had grade 4 mMRC dyspnea, 48 (42.1\%) had grade 3, 30 (26.3 \%) had grade 3 and only 4 (3.5 \%) had grade 1 dyspnea. Of the total 114 patients 110 (96.5\%) patients had grade 2 or more dyspnea. The mean years of occurence of dyspnea is 10.3 years.

Table 1. Basic parameters

\begin{tabular}{|l|l|l|l|l|l|}
\hline Parameter & Mean & $\begin{array}{l}\text { Std } \\
\text { Deviation }\end{array}$ & Median & $\begin{array}{l}\text { Minim } \\
\text { um }\end{array}$ & $\begin{array}{l}\text { Maxim } \\
\text { um }\end{array}$ \\
\hline Age (in years) & 64.7 & 7.7 & & & \\
\hline Sex (male/female) & $109 / 5$ & & & & \\
\hline $\begin{array}{l}\text { Smoking } \\
\text { (never/ex/current) }\end{array}$ & $1 / 85 / 28$ & & & & \\
\hline FEV1 & $40.9 \%$ & 14.7 & 38.3 & 18 & 79 \\
\hline
\end{tabular}


Texila International Journal of Medicine Volume 5, Issue 1, Jun 2017

\begin{tabular}{|l|l|l|l|l|l|}
\hline Respiratory rate & 25.3 & 5.4 & 24.0 & 16 & 40 \\
\hline $\begin{array}{l}\text { GOLD Stage } \\
(1 / 2 / 3 / 4)\end{array}$ & $\begin{array}{l}0 / 32 / 50 / \\
32\end{array}$ & & & & \\
\hline $\begin{array}{l}\text { GOLD Class } \\
\text { (A/B/C/D) }\end{array}$ & $\begin{array}{l}1 / 10 / 2 / 1 \\
01\end{array}$ & & & & \\
\hline Hemoglobin & 13.1 & 1.7 & 13.0 & 9.4 & 17.8 \\
\hline Sodium & 135.0 & 7.2 & 136.5 & 110 & 152 \\
\hline Potassium & 4.1 & 0.7 & 4.1 & 2.9 & 5.7 \\
\hline Magnesium & 1.8 & 0.3 & 1.9 & 0.9 & 2.7 \\
\hline Urea & 33.2 & 23.8 & 27.0 & 12 & 146 \\
\hline Creatine & 0.9 & 0.4 & 0.8 & 0.5 & 3.1 \\
\hline Ph & 7.4 & 0.1 & 7.4 & 7.145 & 7.516 \\
\hline $\begin{array}{l}\text { PO2 } \\
\text { PCO2 }\end{array}$ & 70.8 & 24.9 & 68.0 & 31.7 & 212 \\
\hline $\begin{array}{l}\text { HCO3 } \\
\text { patient }\end{array}$ & 47.7 & 15.0 & 45.1 & 19.2 & 93.7 \\
\hline $\begin{array}{l}\text { Days of } \\
\text { hospitalization }\end{array}$ & 26.6 & 6.2 & 25.9 & 10 & 41.2 \\
\hline $\begin{array}{l}\text { Rost during } \\
\text { Rstay }\end{array}$ & 5.4324 .618 .0 & 835.3 & 500.0 & 0 & 7000 \\
\hline
\end{tabular}

Manual labor involving agriculture is the most common occupation accounting to $62.3 \%$ of patients. The mean year of retirement from occupation is 7.7 years. $70(60 \%)$ of patients have to stopped their work for more than 5 years. The most common co-morbidities observed in our study are systemic hypertension (10.5\%) and coronary artery disease $(9.6 \%)$. Type 2 diabetes mellitus were found in $6.1 \%$ of cases. Of the 114 patients $92(80.7 \%)$ had 1 or more hospitalizations in the previous years. 22 (19.35) had no COPD exacerbation in the past one year. Only 8 (7\%) of the 114 patients were using long term oxygen therapy. 28 (24.6\%) patients were current smokers while 85 (74.6\%) patients were ex-smokers. 90 (78.9\%). The mean BMI value in the study group is 19.8 and 55 (48.2 \%) patients have low BMI.

Table 2. Immediate mortality during admission

\begin{tabular}{|l|l|l|l|}
\hline Parameter & $\begin{array}{l}\text { Univariate } \mathrm{p} \\
\text { value }\end{array}$ & $\begin{array}{l}\text { Odds ratio/T } \\
\text { value }\end{array}$ & $\begin{array}{l}\text { Multivariate } \mathrm{P} \\
\text { value }\end{array}$ \\
\hline $\begin{array}{l}\text { Respiratory rate }> \\
27\end{array}$ & .005 & .046 & .032 \\
\hline FEV1<35 & .035 & .101 & .245 \\
\hline Urea $>74.5$ & 0.000 & .039 & .046 \\
\hline Creatinine $>0.95$ & .067 & .248 & .917 \\
\hline Age & .414 & .819 & \\
\hline BMI & .770 & .293 & \\
\hline Sodium & .110 & 1.612 & \\
\hline
\end{tabular}




\begin{tabular}{|l|l|l|l|}
\hline Potassium & .303 & .703 & \\
\hline PaCO2 & .283 & .777 & \\
\hline Magnesium & .50 & .670 & \\
\hline $\mathrm{pH}$ & .799 & .255 & \\
\hline $\mathrm{PaO} 2$ & .924 & .328 & \\
\hline
\end{tabular}

The in-hospital mortality was 7\% (8 of 114), the factors associated with in-hospital mortality are higher respiratory rate ( $p$ value $=0.005$ ), lower FEV1 ( $p$ value $=0.035$ ) and high urea level ( $p$ value $<0.001$ ). Multivariate analysis showed that higher respiratory rate and blood urea value are the factors associated with in-hospital mortality.

Table 3. Days of hospital admission $>5$ days

\begin{tabular}{|l|l|l|l|}
\hline Parameter & $\begin{array}{l}\text { Odds ratio/t } \\
\text { Value }\end{array}$ & $\begin{array}{l}\text { Univariate } \\
\text { p value }\end{array}$ & $\begin{array}{l}\text { Multivariate P } \\
\text { value }\end{array}$ \\
\hline Respiratory rate $>23$ & 0.388 & 0.04 & .164 \\
\hline PaCO2>45.85 & 4.377 & 0.001 & .004 \\
\hline $\begin{array}{l}\text { X-RAY } \\
\text { CONSOLIDATION }\end{array}$ & 5.859 & 0.04 & .079 \\
\hline Age & .369 & .713 & \\
\hline BMI & -1.731 & .086 & \\
\hline FEV1 & -1.588 & .067 & \\
\hline Na & -1.452 & .149 & \\
\hline $\mathrm{K}$ & -1.376 & .172 & \\
\hline Mg & -1.860 & .065 & \\
\hline pH & -1.670 & .098 & \\
\hline HCO3 & 1.839 & .069 & \\
\hline Urea & 1.780 & .078 & \\
\hline Creatinine & .683 & .496 & \\
\hline
\end{tabular}

50 (43.8\%) out of 114 patients had prolonged hospital stay (>5 days). The factors associated with prolonged hospital stay are higher respiratory rate (p value 0.04 ), hypercapnia ( $p$ value 0.001 ) and chest $x$-ray features of consolidation ( $p$ value 0.04 ).

Table 4. Days on non invasive ventilation $>5$ days

\begin{tabular}{|l|l|l|}
\hline VARIABLE & T value / Exp B & P value \\
\hline Respiratory rate & -.408 & .685 \\
\hline PaCO2 & 0.083 & .934 \\
\hline FEV1 & -.213 & .832 \\
\hline HCO3 & -1.942 & .057 \\
\hline Ph & -1.275 & .207 \\
\hline Sodium & -.019 & .985 \\
\hline Potassium $<4.0$ & 4.500 & .007 \\
\hline Magnesium & -1.780 & .080 \\
\hline
\end{tabular}

63 of the 114 patients needed NIV, and the average days of NIV 5.6 days. 24 of the 63 cases had prolonged NIV ( $>5$ days). The only factor significantly associated with prolonged NIV is low potassium value ( $\mathrm{p}$ value $<0.05$ ).

12 out of 114 patients required invasive mechanical ventilation. The factors associated with the need for invasive mechanical ventilation are higher respiratory rate ( $p$ value 0.001), hypercapnia ( $\mathrm{p}$ value $<0.05$ ), hyponatremia ( $\mathrm{p}$ value $<0.044$ ), and higher values of creatine ( $\mathrm{p}$ value $<0.05)$. 
Three month mortality was accessed by telephonic interview by the observer. Of the total 114 patients selected for the study 40 patients could not be contacted. Of the 74 patients we could contact 19 (25.7\%) patients died within three months from current hospital admission. In Multiple logistic and Cox regression analysis, only FEV1 (p value $=0.031$, odds ratio 12.25, and hazard ratio 10.27) and respiratory rate ( $p$ value $=0.002$, odds ratio 10.76 and hazard ratio 5.53) are independently related to three month mortality. That is FEV1 $<365 \%$ and respiratory rate $>29$ are the independent predictors of three month mortality.

The mean cost of the exacerbation for which the patient is admitted is \$134 (Rs.8324.5), with minimum amount $\$ 87$ (Rs.5381.0)

Table 5. Results of *ROC Analysis of three months survival

\begin{tabular}{|l|l|l|l|l|l|l|}
\hline & AUC & Sensitivity & Specificity & PPV & NPV & Accuracy \\
\hline mMRC $>=4$ & 0.589 & 36.8 & 76.4 & 35.0 & 0.8 & 66.2 \\
\hline RR $>=29$ & 0.744 & 57.9 & 89.1 & 64.7 & 0.5 & 81.1 \\
\hline BMI $<=18.5$ & 0.543 & 63.2 & 54.5 & 32.4 & 0.7 & 56.8 \\
\hline FEV1 $<36 \%$ & 0.714 & 94.7 & 50.9 & 40.0 & 0.1 & 62.2 \\
\hline $\begin{array}{l}\text { Magnesium } \\
<1.8\end{array}$ & 0.551 & 63.2 & 47.3 & 29.3 & 0.8 & 51.4 \\
\hline
\end{tabular}

Table 6 Impact of Recorded Variables in Categories (from ROC* Analysis) on Three-year Mortality Using Multiple Logistic Regression Analysis and Cox Regression Analysis

\begin{tabular}{|c|c|c|c|c|}
\hline & \multicolumn{2}{|c|}{ Multiple Logistic Regression } & \multicolumn{2}{|c|}{ Cox Regression Analysis } \\
\hline & OR (95 \% CI) & $\mathrm{p}$ & HR (95 \% CI) & $\mathrm{p}$ \\
\hline $\begin{array}{l}\text { MMMRC } \\
>=4\end{array}$ & $1.1(0.28-4.25)$ & 0.894 & $1.14(0.43-3.02)$ & 0.794 \\
\hline $\mathrm{RR}>=29$ & $10.76(2.44-47.38)$ & 0.002 & $5.53(2.13-14.34)$ & 0.0004 \\
\hline BMI $<=18.5$ & $2.87(0.63-13.05)$ & 0.173 & $1.6(0.57-4.49)$ & 0.372 \\
\hline FEV1 $<36 \%$ & $\begin{array}{l}12.25(1.26- \\
118.83)\end{array}$ & 0.031 & $10.27(1.32-80.11)$ & 0.026 \\
\hline $\begin{array}{l}\text { Magnesium } \\
<1.8\end{array}$ & $1.24(0.3-5.04)$ & 0.764 & $0.8(0.27-2.31)$ & 0.674 \\
\hline
\end{tabular}

Graph Showing ROC Analysis on Three-year Mortality for Respiratory Rate $>29$ and FEV1<36\% 


\section{ROC Curve}

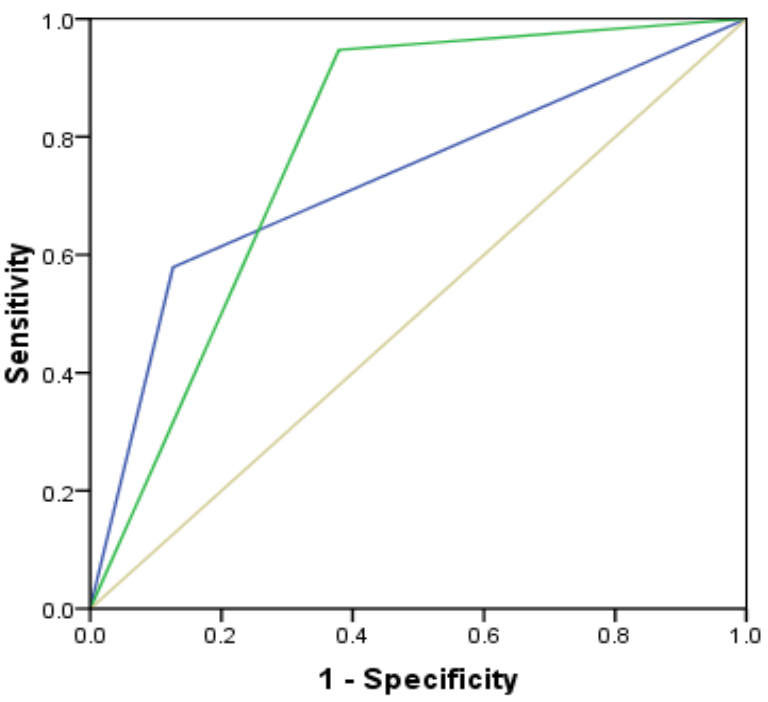

Source of the Curve

- RespiratoryRate

- FEV1

Reference Line

Diagonal segments are produced by ties

\section{Discussion}

Chronic obstructive pulmonary disease is a major cause of health care burden worldwide and the only leading cause of death that is increasing in prevalence. Acute exacerbation of COPD is a common cause of emergency department visit and hospital admission. Following an acute exacerbation majority of patients experience a temporary or permanent decrease in quality of life. More than half of the patients discharged with AECOPD often require readmission in the subsequent six months. The variability in the outcome and course of AECOPD even in patients with similar degree of pulmonary impairment renders the prediction of outcome in a given patient very difficult. Though AECOPD is an important cause of emergency department visits and hospital admission in India only very few studies were published about the outcomes and predictors of outcome in AECOPD from India, particularly from state of Kerala. This study is an observational study on outcome of AECOPD and the predictors of outcome in AECOPD.

The in-hospital mortality was 7\% (8 of 114), the factors associated with in-hospital mortality are higher respiratory rate ( $p$ value $=0.005$ ), lower FEV1 ( $p$ value $=0.035$ ) and high urea level ( $p$ value $<0.001$ ). Multivariate analysis showed that higher respiratory rate and blood urea value are the factors associated with in-hospital mortality. Study by Angeliki M Tsimogianni et al obtained the in-hospital mortality was 4.9\% (4/81 patients). Present study has slightly higher in-hospital mortality than this study, probably because in our study majority of patients were in higher Gold stage.

50 (43.8\%) out of 114 patients had prolonged hospital stay ( $>5$ days). The factors associated with prolonged hospital stay are higher respiratory rate (p value 0.04 ), hypercapnia ( $\mathrm{p}$ value 0.001 ) and chest $\mathrm{x}$-ray features of consolidation ( $\mathrm{p}$ value 0.04 ). Similar study by Angeliki M Tsimogianni et al observed that $33.33 \%$ of patients had prolonged hospital stay. The factors significantly associated with prolonged hospital stay are, BMI, MRC score, LTOT, and PaCO2. In our study there was no association between BMI, mMRC score, and LTOT with prolonged hospital stay.

63 of the 114 patients needed NIV, and the average days of NIV 5.6 days. 24 of the 63 cases had prolonged NIV ( $>5$ days). The only factor significantly associated with prolonged NIV is low potassium value ( $p$ value $<0.05$ ). That is hypokalemia is associated with prolonged NIV use. 
12 out of 114 patients required invasive mechanical ventilation. The factors associated with the need for invasive mechanical ventilation are higher respiratory rate ( $\mathrm{p}$ value o.oo1), hypercapnia ( $\mathrm{p}$ value $<0.05$ ), hyponatremia ( $\mathrm{p}$ value $<0.044$ ), and higher values of creatine ( $\mathrm{p}$ value $<0.05)$.

Of the total 114 patients selected for the study 40 patients could not be contacted. Of the 74 patients we could contact 19 (25.7\%) patients died within three months from current hospital admission. Low FEV1 (FEV1 < 36.5\%) and higher respiratory rate $>29$ ) are the independent predictors of three month mortality. Both these factors can be easily accessed for all patients. Special attention may be given to patients having these bad predictors of outcome and which may help them to recover from.

Similar study by Angeliki et al done in Greece found out that the BMI and MRC dyspnea scale are the independent predictors of three year mortality. Study by Kim S et al on Mortality after an emergency department visit for chronic obstructive pulmonary disease observed that the three year mortality is independently associated to age, specific co-morbid conditions and history of prior COPD exacerbations.

\section{CONCLUSION}

The factors associated with in-hospital mortality are higher respiratory rate, lower FEV1 and high blood urea level. Hypokalemia is associated with prolonged days of NIV usage. Three month mortality following AECOPD is related to higher respiratory rate, and low FEV1 value. The mean cost of an AECOPD in our study is \$134.

\section{References}

[1]. Burge S, Wedzicha JA. COPD exacerbations: definitions and classifications. Eur Respir J Suppl 2003; 41:46s-53s.

[2]. Celli BR, Barnes PJ. Exacerbations of chronic obstructive pulmonary disease. Eur Respir J 2007; 29:1224-38.

[3]. Chronic Obstructive Pulmonary Disease, COPD; Acute Exacerbation of Chronic Obstructive Pulmonary Disease, AECOPD; Non Invasive Ventilation, NIV; Global Initiative for Chronic Obstructive Lung Disease, GOLD; Body Mass Index, BMI; Forced Expiratory Flow in first second, FEV1; Modified Medical Research Council, mMRC ;Long Term Oxygen Therapy, LTOT ;Partial pressure of oxygen, $\mathrm{PaO} 2$;Partial pressure carbon dioxide, $\mathrm{PaCO} 2$;Bicarbonate, HCO3.

[4]. GOLD COPD-- Global strategy for Diagnosis, Management, and Prevention of Chronic Obstructive Pulmonary Disease revised 2014. http://www.goldcopd.com/

[5]. Jindal SK, Agarwal AN, Gupta D. A review of population studies from India to estimate national burden of chronic obstructive pulmonary disease and its association with smoking. Indian J Chest Dis Allied Sci. 2001;43(3):139-47

[6]. Kessler R, Stahl E, Vogelmeier C, et al. Patient understanding, detection, and experience of COPD exacerbations: an observational, interview-based study. Chest 2006; 130:133-42.

[7]. Lopez AD, Shibuya K, Rao C, et al. Chronic obstructive pulmonary disease: current burden and future projections. Eur Respir J 2006; 27:397-412.

[8]. Murthy KJ, Sastry JG. Economic burden of chronic obstructive pulmonary disease. NCMH Background Papers- Burden of Diseases in India; 2005.pp. 264-74.

[9]. Rodriguez-Rosin R. Toward a concensus definition for COPD exacerbations. Chest2000; 117:398S-401S.

[10]. Spencer S, Calverley PM, Burge PS, Jones PW. Impact of preventing exacerbations on deterioration of health status in COPD. Eur Respir J 2004; 23:698-702.

[11]. Seemungal TA, Donaldson GC, Bhowmik A, Wedzicha JA. Time course and recovery of exacerbations in patients with chronic obstructive pulmonary disease. Am J Respir Crit Care Med 2000; 161:1608-13.

[12]. Smetana MM. Preoperative pulmonary evaluation. N Engl J Med 1999; 340:937-44.

[13]. Kanner RE, Anthonisen NR, Connett JE. Lower respiratory illness promote FEV1 decline in current smokers but not ex-smokers with mild chronic obstructive pulmonary disease: results from the lung health study. Am J Respir Crit Care Med 2001; 164:358-64. 
[14]. Textbook of Pulmonary and Critical Care Medicine: First edition 2011; SK Jindal.

[15]. World health report. Geneva: World Health Organisation. Available from URL http://www.who.int/whr/2000/en/statistics.htm;2000

[16]. Wourers EF. The burden of COPD in Netherlands: results from the Confronting COPD survey. Respir Med 2003; 97 Suppl C:S51-9. 